\title{
Are There "Stages of Change" in the Practice of Female Genital Cutting?: Qualitative Research Findings from Senegal and The Gambia
}

\author{
Bettina Shell-Duncan and Yiva Herniund
}

\begin{abstract}
In recent years there has been growing interest in developing theoretical models for understanding behaviour change with respect to the practice of female genital cutting (FGC). Drawing on extensive qualitative data collected in Senegal and The Gambia, the research reported here explores whether and how theoretical models of stages of behaviour change can be applied to FGC. Our findings suggest that individual readiness to change the practice of FGC is most clearly seen as operating along a continuum, and that broad stages of change characterise regions or segments of this continuum. Stages identified by previous researchers for other "problems behaviours" such as smoking inadequately describe readiness to change FGC since this decision is often a collective rather than individual one. The data reveal that the concept of stage of change is a complex construct that simultaneously captures behaviour, motivation, and features of the environment in which the decision is being made. Consequently stages identified in this research reflect the multidimensional nature of readiness to change the practice of FGC. Limitations of stage of change models as applied to FGC include the fact that they do not capture important aspects of the dynamics of negotiation between decision-makers, and do not reflect the shifting nature of opinions of individuals or the constellation of decision-makers. Nonetheless, we suggest the application of stage of change theory may provide a useful means of describing readiness for change of individual decisions-makers and at an aggregate level, patterns of readiness for change in a community. How this construct can be employed in quantitative population research requires further investigation. (Rev Afr Santé Reprod 2006; 10[2]:57-71)
\end{abstract}

\section{RÉSUMÉ}

Y a-t-a il "trois stades de modifications" dans la pratique de l'excission génitale féminine? Les résultats des recherches qualitatives du Sénégal et de la Gambie. Ces dernières années, l'intérêt s'accrôit par rapport à l'élaboration des modèles théoriques pour la compréhension de la modification de comportement à l'égard de la pratique de la mutilation génitale féminine (MGF). Se fondant largement sur les données qualitatives recueillies au Sénégal et en Gambie, la recherche dont il s'agit ici cherche à savoir si et comment les modèles théoriques des stades de la modification du comportement peuvent s'appliquer à la MGF. Nos résultats démontrent que la modification de la pratique de la MGF se manifeste clairement. Dairement comme s'opérant le long d'un continuum et que des modifications diverses caractérisent les régions et les sections de ce continuum. Les stades qui ont été identifiés par les chercheurs précedents pour les "comportements des autres problèmes" tels que le tabagisme ne décrivent pas suffisanment l'empressement à modifier la MGF puisque cette décision est souvent une décision collective plutôt qu'individuelle. Les données révèlent que le concept du stade de modification est une notion complexe qui capte simultanément le comportement, la motivation et les caractéristiques de l'environment dans laquelle on prend la décision. En conséquence, les stades identifiés dans cette recherche reflète la nature dimensionnelle de l'empressement à modifièr la pratique de MGF. Les limitations des stades de modèles de modification telle que cela s'applique à la MGF comprend le fait qu'elles ne captent pas les aspects importants de la dynamique de négociation entre les décisionnaires et ne reflètent pas la nature changeante des opinions des individus ou la constellation des décisionnaires. Néanmoins, nous suggérons que la théorie du stade de modification peut fournir un moyen efficace de décrire l'empressement à la modification des décisionnaires individuels et sur le plan global, les modèles pour la modification dans une communauté. Il sera nécessaire de pousser davantage l'enquête pour voir comment cette notion peut être employée dans la recherche basée sur la population quantitative. (Rev Afr Santé Reprod 2006; 10[2]:57-71)

KEY WORDS: Female genital cutting, Trans-theoretical model, stage of change, decision-making, Senegal, The Gambia.

Corresponding Author: Bettina Shell-Duncan University of Washington Department of Anthropology Box 353100 Seattle,WA98195-3100 U.S.A. Phone: 206-543-9607 FAX: 206-543-3285 bsd@u.washington.edu 


\section{Introduction}

The global movement to eliminate the practice of female genital cutting (FGC) - also referred to as female "circumcision" or "female genital mutilation" (FGM) - has reached a point of increased critical reflection, involving the reassessment of intervention approaches, reappraisal of priorities, and resetting of goals. Widely recognized is the fact that there has been "greater success in raising awareness about the issue than in changing behaviour" , a surprising and perplexing finding given the volume of resources and now decades of effort aimed at eliminating female genital cutting practices. A recent $\mathrm{WHO}^{2}$ review ("Programmes to Date") poses a question asked by many: "What Works and What Doesn't?" In addressing this question, a lack of understanding of decision-making and behaviour change regarding FGC becomes apparent. A recent overview of intervention efforts ${ }^{3}$ notes that, for the most part, "interventions have been implemented with little attempt to...elucidate their impact on knowledge, beliefs, attitudes and behaviours," and proceeds to argue that theoretical models of behaviour change are needed to understand why and how interventions cause change (p. 1$)^{3}$. The purpose of this paper is to explore whether and how theoretical models of stages of behaviour change can be applied to the case of FGC, drawing on data from a current West African research study on decision-making.

Across the social and health sciences, a number of cognitive models have been developed to analyse the process of behaviour change for a wide variety of "problem behaviors." These models employ the concept of "readiness to change" (RTC), which refers to the degree to which an individual is motivated to change a problem behaviour such as smoking or substance abuse $^{4}$. RTC can be conceptualised as an index of the willingness or behavioural readiness to initiate behaviour change ${ }^{4}$. In recent decades, as the construct of RTC has become increasingly popular, cognitive models have proliferated. These include the Health Belief Model ${ }^{5}$, Theory of Planned Behaviour ${ }^{6}$, and the Theory of Reasoned Action ${ }^{7}$. Two recent reports ${ }^{2,8}$ have raised the issue of potentially employing cognitive models to analyse the outcome of FGC interventions, although, to our knowledge, research extending this model to FGC has not been conducted. Discussions have centered on two distinct, but interrelated, models for describing the adoption of behaviour change: diffusion theory, and the trans-theoretical model.

\section{Diffusion Theory}

Diffusion theory analyses the "process by which an innovation is communicated through certain channels over time among members of a social system" (p. 10). One particular area of focus of diffusion theory is the decision to adopt a novel or innovative behaviour. Rogers (p. 162) notes that diffusion scholars have long recognised that an individual or decision-making group passes through a sequence and that a "decision about innovation is not an instantaneous act. Rather it is a process that occurs over time." This decisionmaking process, observed over a wide range of behaviours, has been described as a potential progression along a series of five stages. The first stage, knowledge, occurs when an individual or decision-making unit is made aware of the existence of the innovative behaviour and gains some understanding of how it functions. In the next stage, persuasion, decision-makers form a favorable or unfavourable opinion of the novel behaviour. The third stage, decision, occurs when an individual or decision-making unit chooses to adopt or reject the innovation. Next, implementation involves putting the innovation into use; and, finally, confirmation occurs when decision-makers seek reinforcement of an innovation-decision or reject the innovation if exposed to conflicting messages or dissatisfaction with the innovation.

\section{Stage of Change}

A second, closely related model, developed in the field of public health, is known as the trans-

African Journal of Reproductive Health Vol. 10 No.2 August 2006 
theoretical model of behaviour change or "stage of change" model. This model was developed by Prochaska and DiClemente ${ }^{10,11}$ as a means of integrating different behaviour change theories used in psychology, with particular reference to smoking cessation. It was noted that all smokers identified a common sequence of stage of change in their efforts to quit smoking. The model proposes five distinct stages of behaviour change:

1) pre-contemplation - not intending to make behaviour changes in the foreseeable future;

2) contemplation - considering behaviour change but not yet making a firm commitment to change;

3) preparation - commitment to behaviour change in the next thirty days but not yet changing behaviour (those in preparation may have also made unsuccessful attempts in the past, but have made small changes);

4) action - successfully changing behaviour; and

5) maintenance - behaviour change sustained over six months.

More recently, a sixth stage - termination - has been proposed to reflect behaviour change with little chance of relapse ${ }^{12}$. The model proposes that individuals in different stages will be influenced by different types of intervention, and that the best intervention will be one that is matched to the person's current stage of change ${ }^{13}$ (but for a counter-example which illustrates a case in which matching the stage to intervention did not appear to help, see ${ }^{14}$ ).

The introduction of the trans-theoretical model to the field of health psychology has sparked enormous research interest, extending this approach to other behaviours such as substance abuse, dietary change, exercise promotion, and safe sex ${ }^{15}$. While some studies have modified the stages (preparation was added after the initial conceptualisation of the stage of change model), a progression through an identifiable sequence of stages has been hypothesised for all behaviours studied $^{10,15}$. Some investigators assess only a subset of stages or subdivide stages for a particular research question ${ }^{4}$, yet the suitability of transferring stages developed with respect to smoking behaviour to other behaviours is often not critically evaluated. Notably, definitions or conceptualisations of stages are not demonstrated to be grounded in qualitative data reflecting the experiences, behaviours, and articulated perspectives of members of the study population.

FGC researchers have begun adopting the concepts and terminologies of diffusion theory and the trans-theoretical model (see, for example, ${ }^{16,17}$ ) despite the fact that there have been no rigorous investigations of whether or how these models are applicable to the case of FGC. This shift is not merely to a new "problem behaviour," but to an extremely different cultural context in comparison to that in which original conceptualisation of stages of change originally formulated, and to a decision that is often a collective rather an individual one.

The goals of this paper are to:

1) consider some of the strengths and limitations of the application of models of readiness to change to the case of female genital cutting; and

2) using qualitative data from our current research in Senegal and The Gambia to discern whether themes identified in content analysis can be interpreted to represent stages of change.

\section{Lessons Learned from HIV Research}

Cognitive models of behaviour change have been extended to the study of behaviour change for a wide variety of behaviours, ranging from smoking cessation to the adoption of new computer technologies, from weight control to condom use, and from the acceptance of novel agricultural techniques to using clean needles when injecting drugs. With extended applications, several models have been extensively revised and refined. Yet, particularly within the last decade, a number 
of scholars have leveled criticisms, most prolifically and thoughtfully with respect to HIV prevention ${ }^{18-23}$. Behavioural interventions to control the transmission of HIV have largely centered on risk reduction through abstinence, being faithful, or condom use (the so-called ABCs of HIV prevention). Several scholars have argued that cognitive theories and models of health behaviour do not provide an adequate framework for promoting the adoption of safe sex; and we suggest that issues problematised in this literature may have several important parallels to the case of FGC.

Yoder $^{23}$ highlights two key assumptions common to cognitive models of behaviour change:

1) the capacity for behaviour change is viewed as being in control of the individual, and it is assumed that if individuals are educated about health risks they will be motivated to change their behaviour; and

2) individuals act rationally in assessing information and risk, and are empowered to take action to protect themselves.

Unlike smoking cessation or the adoption of preventive medical care, safe sex (except for the case of abstinence) is not something that individuals engage in alone. Airhihenbuwa and colleagues (cited in ${ }^{18}$ ) argue that the assumption that individuals can or will exercise total control over their behaviour has led to a focus on the individual rather than on the social context in which the individual functions. This viewpoint has been dubbed the "individualist fallacy" by Davies $^{19}$, who also points out that the interpersonal activity is preceded by a "complex social negotiation, which we understand poorly."

He further suggests that "it is more fruitful to seek the causes of a particular sexual behaviour in the interaction between individuals," rather than in characteristics of the individual ${ }^{19}$ ( $p$ 135). This suggests that the unit of analysis is more appropriately the interaction in a sexual session, as opposed to specific cognitive characteristics of an individual ${ }^{23}$. Emphasis on the negotiating aspects of sexual encounters draws attention to the dynamics of interpersonal power, and raises the issue of self efficacy, the extent to which individuals have control over the course of events ${ }^{20}$. Yoder (p. 134) ${ }^{22}$ emphasises that, in cognitive models, "most social behaviour is assumed to be based on volition, and very closely linked to intention to perform that behaviour." Yet for sexual encounters, this may not be the case. As Parker $^{18}$ (p. 2) notes, "Sexual interactions take place in a wide range of contexts and along a continuum of consent that extends from willed or conscious engagement in sexual activity through to unwilled non-consensual sex, that include the use of coercion and possibly physical violence." With respect to consensual sex, Davies ${ }^{19}$ notes that sexual negotiation is not necessarily between equals. Instead, there exist situations in which one individual becomes more able to decide the course of events than the other, and the decision-making power is not fixed over time, but continuously renegotiated, even between the same two individuals. As Yoder ${ }^{23}$ points out, however, most cognitive models "assume individuals make a once-and-for-all decision to have safe sex... (and) minimise the negotiating aspects of sexual acts." Similarly Parker ${ }^{18}$ (p2) argues that behaviour change cannot be assumed to be consistently maintained, and emphasises that the "complexity of sexual relationships and interactions over a lifetime. . . are influenced by diverse changing contexts - for example changing partnerships, changing relative empowerment/ disempowerment." Consequently, individual intention is mediated by this shifting power dynamic, influenced by interpersonal actors, as well as fluctuating social and political realities.

The second broad assumption of cognitive behaviour change models - that individuals educated about risks will act rationally - has also been called into question. Ingham and colleagues ${ }^{20}$ (p. 164) point out the narrow use of the concept

African Journal of Reproductive Health Vol. 10 No.2 August 2006 
of rationality in behaviour change theory: "Campaigns and interventions rest on the assumption that 'correcting' false beliefs and misconceptions will enable any 'rational' person to alter their behaviour in the 'desired' direction." Missing from this formulation of rationality is the fact that individuals may have valid reasons for not complying with the advice, or may have other factors constraining or motivating their behaviour. Ingham, et. al..$^{20}$ (p. 168) thus describe "varied rationalities" that may be "at odds with and counteract the 'received rationality' of official biomedical wisdom." This, again, points to the fact that decisions are made in the context of broader social and political realities that also influence decision-making. While some models have been extended to attempt to address this by adding sociodemographic variables, Yoder ${ }^{22}$ concludes that "factors of social relations and ecological context are given short shrift."

Along with Davies ${ }^{19}$, Yoder emphasises the utility of focusing on social interaction for understanding behaviour change and elucidating contexts in which specific actions are negotiated or imposed. He concludes that focused ethnographic methods are essential to understanding behaviour in its social contexts and requires the development of a "common sense knowledge of the world that may take a quite different form from our own."

\section{From HIV to FGC: What Can We Learn?}

Issues of individualism, self efficacy, negotiation and power pertain to the application of decision making models to FGC. Several commentators (e.g. ${ }^{2,8,24}$ ) note, quite importantly, that behaviour change in the case of FGC is fundamentally different from that for individually based behaviours such as smoking or alcohol cessation, since decisions are often made by a larger group. Clearly any analysis of decision-making regarding FGC must consider readiness for change among multiple stakeholders in the decision to abandon FGC.

African Journal of Reproductive Health Vol. 10 No.2 August 2006
We argue that a focus on the individual may not be entirely inappropriate with respect to FGC, but instead it is simply not the final point of analysis. Individuals bring to the negotiation process their own perspectives and opinions that have been shaped by a unique repertoire of experiences and sources of influences, as well as greater or lesser skills in communication, powers of persuasion, and varying degrees of power and authority in decision-making. The question, then, is: how do individual attributes and opinions influence social interactions and the dynamics of negotiation? Who makes up the constellation of decision-makers, and how does this change over time? How can we best describe an individual?s readiness for change?

Identification of the readiness to change of individuals may be useful for making aggregate descriptions of a community - is it one that is largely receptive to change, or are many residents resistant to change? This may provide useful information regarding the immediate social environment in which decision-makers are operating.

\section{Study Population}

This study analyses data collected in a current mixed-method qualitative study of decisionmaking and behaviour change with respect to the practice of FGC in the West African nations of Senegal and The Gambia. Both countries have remained independent nation states since their independence in the 1960's from France and Britain respectively. Nonetheless, they are often collectively referred to as Senegambia, owing to the fact that they share much in common in terms of culture, landscape, and climate (although the political entity of the senegambian federation broke up in 1989). The tiny nation of The Gambia is a long thin strip of land extending from the Atlantic coast inward 300 kilometers along the banks of the Gambia River, constituting an enclave that nearly bisects the larger nation of Senegal. 
Despite the fact that the two countries vary in colonial history, size, and official language, as well as political and economic circumstances, its populations share, as well, many characteristics, including local languages, dominant religion (over 90\% Muslim in both), subsistence activities, and cultural practices. Along the long border can be found, on either side, communities sharing very similar characteristics and even extended families living divided on different sides of the political boundary.

As the practice of FGC is most closely tied to ethnic affiliation, the overall prevalence rates for The Gambia and Senegal vary. For example, the Wolof, who largely do not practice FGC, make up only $16 \%$ of the Gambian population, but form the ethnic majority (43\%) in Senegal; while the Mandinka, who almost universally practice FGC, constitute $42 \%$ of the population in The Gambia, and a much smaller proportion in Senegal (less than 19\%). Consequently, the prevalence of FGC at the national levels varies dramatically. In The Gambia a strong majority of the population (over 80\%) practices FGC, whereas in Senegal it has been a minority of $20 \%{ }^{25,26}$

In addition, the two countries have experienced very different trajectories regarding campaigns to eliminate FGC. Senegal is the site of the massive Tostan project, which is reported to have made significant progress in eliminating FGC. As of 2005, Tostan-led public declarations have been held in approxi-mately 1,500 villages, with participants pledging to abandon the practice of FGC (www.tostan.org). This phenomenon does not, however, appear to have spread across the frontier to Gambian communities that otherwise have much in common with their Senegalese neighbours.

Although anti-FGM campaigns in The Gambia date back several decades, there is no evidence of large-scale abandonment of the practice there. Nonetheless, there exist individual cases of abandonment as well as of adoption; and debates as to whether and how to perform
FGC are active and often heated, as the meanings and motivations for continuing the practice are called into question. In another divergence between the two countries, Senegal has passed legislation against FGC within the country, although it is not a crime to perform the practice abroad. By contrast, the Gambian government has not and does not appear to intend to pass any such legislation. Thus, this border area provides a unique research site for examining the diffusion (or lack thereof) of anti-FGM messages and behaviour change.

The research is being conducted in three distinct regions:

1) the peri-urban communities surrounding the Gambian capital, Banjul;

2) the Gambian North Bank Division border area and

3) the Senegalese region directly across the northern Gambian border from the North Bank.

Prior to beginning work in this border region of Senegal, we had envisioned that there would be large sections of the country that had either been targeted or not by Tostan and other anti-FGM interventions. This turned out to not be the case, as it is often true that one village that has participated in the program neighbours others that have not. This is partly attributable to ethnic variation: one village dominated by Mandinka residents who traditionally practise FGC might be located less than a mile from another village comprised of largely non-practising Wollofs. Moreover, it is not the case that all practising villages in one area participated in the intervention programme. Therefore, the picture that emerges is more of a patchwork of villages that have or have not participated in the intervention programme rather than neatly concentric areas of diffusion.

\section{Methods}

The first phase of the research involved qualitative research in each subsection of the study region.

African Journal of Reproductive Health Vol. 10 No.2 August 2006 
Data were collected by six Gambian fieldworkers supervised by a Gambian field manager, all of whom grew up in families where FGC is practised. They received training in qualitative research methods from Ylva Hernlund. One male and one female fieldworker were assigned to each of the three study sites and, for fieldworkers in the border region, lodging was obtained so that they could become temporary residents in their study sites. Their activities were coordinated by the field manager, who negotiated entry to the study communities, reviewed transcripts, and clarified questions that arose from transcripts. Gaining access to the study sites was facilitated by the fact that members of our research team often had family connections in the study sites. Consequently, the fieldworkers were quickly able to become accepted in the study communities, and residents were in most cases willing to participate in interviews and focus group discussions (FGDs).

Research techniques consisted of observation while living in the study communities (fieldworkers wrote field journals containing information on the village setting and activities in general) and interviews to obtain case histories of decision-making regarding the nature and practice of FGC. The transcripts were typed and coded at the University of Washington using Atlas $\mathrm{ti}^{\circledR}$ qualitative data analysis software. Interviews were completed with both adult men and women involved in the decision-making process. In addition, focus group discussions were conducted in order to identify perceptions regarding social norms, advantages and disadvantages of FGC, and recent changes in the practice. The qualitative data collection yielded over 300 interviews, and twenty-eight focus groups with five to seven participants each. The interviews and focus groups contain tremendously rich information on decision-making and the broader contexts of factors influencing whether and how the practice of FGC is changing. We summarise here findings that are particularly relevant to examining whether

African Journal of Reproductive Health Vol. 10 No.2 August 2006 or in what manner there exist "stages of change" in the practice of FGC. First, however, we describe the context or arenas of decision-making, as well as the constellation of decision-makers.

\section{Arenas of Decision-Making}

When we originally conceptualised this research project, we anticipated that a main arena of decision-making would be among parents or family members regarding whether, when, or how to circumcise a young daughter. We find that this is indeed the case. However, two additional arenas of decision-making have been identified, initially in Hernlund's previous work ${ }^{27}$ and confirmed by findings of the current study. Interviews have revealed that the question of whether FGC should be performed may arise after marriage, particularly in instances of interethnic marriage (which is neither rare nor problematic in any of our study sites) between members of circumcising and non-circumcising groups. In several instances, co-wives and/or female relatives of the husband arranged for the circumcision of the new wife. Uncircumcised women who live with circumcised co-wives or in-laws often report being contemptuously insulted as solema, an extremely powerful invective meaning not only "uncircumcised," but also rude, ignorant, immature, uncivilised, and unclean $\left(\mathrm{see}^{27}\right)$. The fear of being labelled as solema acts as an extremely strong motivation for a woman to "join" herself or her daughter with those who are circumcised. Additionally, women who are not circumcised are not able to participate in the initiation of their own daughters, and women were not uncommonly motivated to agree to being circumcised in order to be allowed such inclusion. Consequently, in a number of instances, FGC is being performed on adult women after they move to reside with their husband's family.

Q: Can you tell me if you remember the time you went?

A: Yes, I was a grown-up. I came here when I got married, I had one child. 
Q: At that time, how old were you?

A: Thirty years. But I did not know, I just found myself in it (Gambian, urban Jola woman in her 50s).

Q: Can you remember when you went to circumcision?

A: Yes, I can remember... At that time I had five children.

Q: You had five children!

A: Yes, when I went.

Q: Can you tell me if you knew what was going to happen before you went?

A: I knew I was going, but I could not understand what was going to happen.

Q: You did not know what they were going to do to you?

A: My mind was already made up that I was going to tear my body. Yes, "I am going to tear my body." I felt it a lot, going up to this stage, then "cut off my body and throw it."

Q: Now can you tell me who made you do this?

A: The person who made me do this is my husband's brother's wife because I was hearing insults. They were telling me "jankadingo" bastard, illegitimate child7. I used to feel bad about it. If you are living with them, you must be insulted if you bave not gone, and I was living with my co-wives. When I told my husband that I was going he did not agree. He did not want me to go. He said to me, "I don't have anything in that," but I went (Young Gambian, urban, Wollof woman who married into a Sereer family).

This phenomenon does not appear to be new, as it can be traced back at least one generation. One elderly Gambian Wollof woman from a rural area recalled from her childhood:

[E]ven ifyou are in the midst of circumcised women, you are isolated at times. For example, there was an uncircumcised woman who got married in the home I was brought up in; anytime she cooked, we did not eat and when we cooked we let her eat alone. And sometimes we always called her "Solima," meaning someone who knows nothing. As a result, she one day went to the [circumciser] and asked her to circumcise her.
A third arena of decision-making involves girls from non-circumcising families who spontaneously join their friends for circumcision (see also Hernlund p.45) ${ }^{27}$. This explains, for example, how FGC is found among a percentage of Wollof women (even prior to marrying), who are generally said to not practise. Our data suggest that this phenomenon of spontaneously "joining" circumcision has become less common in recent years, partly in response to anti-circumcision campaigns. While FGC was previously performed on young girls in groups and accompanied by public celebration, more recently there is a tendency to perform it at younger ages (even on infants) privately in the home. This has diminished the opportunity for "joining." However, for adult women who joined their friends at a young age, the decision as to whether their daughters will be circumcised is influenced by the fact that FGC "is not their tradition."

\section{Constellation of Decision-makers}

At the outset we anticipated finding some differences in the constellation of decision-makers in urban versus rural settings. Daffeh, et. al. point out that the, "communal way of life in the rural areas prevents any radical departures from community values and norms," and adds that it "would be easier for an anti-FGM protagonist to survive in the peri-urban and urban areas than in the agrarian rural communities" (p. 35) ${ }^{26}$. It might thus be expected that in the urban setting the decision regarding FGC would more commonly rest within a nuclear family. We find, however (as did Hernlund) ${ }^{27}$, that in both rural and urban settings the decision is most often shared with extended family members. Grandmothers and paternal aunts, in particular, often exert considerable influence. For instance, in one Senegalese site several young women said that, before the law, even if they did not agree with the decision of the grandmother, they could not oppose it because of respect for their elders. In some cases men were identified as participants

\footnotetext{
African Journal of Reproductive Health Vol. 10 No.2 August 2006
} 
in the decision-making process, but much more commonly the decision was regarded as a "women's affair."

Decision-making in some instances results from achieving consensus among decisionmakers. In other cases, individuals can act against the will of others and take a girl to circumcision despite the opposition of other family members. In particular, when there is a lack of agreement among decision-makers, those who do not want a girl to be circumcised are often on constant vigil to prevent the girl from being "taken." A female participant in a rural FGD in The Gambia explained:

I once encountered difficulties. My younger sisters went to circumcision, and one girl followed them. This girl came from a family that did not practice FGC and even believed that going through the process would result in death, because it is against their culture. So, when this girl followed my sisters, we took her to circumcision, and when her mother heard the news, she came attacking me, and even wanted to take me to the police. I asked her [the mother] to take me anywhere her legs could carry her. It was her daughter who followed us to where we were and, of course, we should and must circumcise her, so we did. Whether it was their taboo or not, this was not our business. It is our traditional duty that we were exercising, and any uncircumcised female that met us there will surely be circumcised. The mother of this girl did say all sorts of things, but the bottom line is that any uncircumcised girl who comes to our place, where our newly circumcised girls are kept, must experience the process by berself. As for us, we do not compromise this issue.

It is important to note, as well, that the constellation of decision-makers is not static, but rather changes over time, as, for instance, relatives migrate into or away from the compound and as girls shift to reside with different relatives or transfer from their natal to marital home.

\section{Stages of Change}

Although scholars have suggested that behaviour change with respect to FGC may be concept-

African Journal of Reproductive Health Vol. 10 No.2 August 2006 ualised in terms of stages of change, no previous research has investigated whether and what identifiable stages can be defined. It has also been questioned whether assessment of stage of change for an individual is meaningful given that the decision to continue or abandon FGC is often not in the hand of individuals, but rather a group of decision-makers. We do, however, find the concept of stage of change to be potentially useful for describing the position of individuals who comprise the decision-making group, and we believe that understanding the degree of concordance, as well as the degree of leverage in the final decision, is potentially useful for comprehending the dynamics of decisionmaking. Our findings reveal that behaviour change with respect to FGC is operating in two directions:

1) some people from families that have traditionally practiced FGC are abandoning the custom, and

2) some people from families that have not previously practiced FGC are newly adopting the practice.

This letter category includes not only girls who spontaneously "join" their peers in circumcision, but also families who live amongst people who practice FGC and become convinced of the benefits of the practice (eg., reduced problems in childbirth, enhanced protection of virginity, training in showing respect). This represents an important divergence between FGC and other behaviours analysed vis-à-vis readiness to change models. Individuals who have adopted smoking, for example, do not appear to do so because they have become convinced of the health benefits of the behavior. (Smoking may, however, reflect a normative behavior in a social group, and adoption may confer, to some extent, social benefits). Consequently, models of behaviour change for GFC need to reflect the fact that behaviour change may be bi-directional.

Our data reveal that the process of behaviour change for individuals is best seen as falling on a 
Table 1: Dimensions of Readiness to Change Female Genital Cutting

\begin{tabular}{|l|l|l|l|l|}
\hline & & \multicolumn{3}{|c|}{ Individual Preference } \\
\hline & & Supports FGC & Ambivalent & Opposes FGC \\
\hline \multirow{4}{*}{ Actual Behavior } & $\begin{array}{l}\text { Has or will circumcise } \\
\text { daughter }\end{array}$ & $\begin{array}{l}\text { Non-Contemplative } \\
\text { (Willing Practitioner }\end{array}$ & & $\begin{array}{l}\text { Reluctant } \\
\text { Practitioner }\end{array}$ \\
\cline { 2 - 5 } & Not Sure & & Contemplative & \\
\cline { 2 - 5 } & $\begin{array}{l}\text { Will not circumcise } \\
\text { daughter }\end{array}$ & $\begin{array}{l}\text { Reluctant } \\
\text { Abandoner }\end{array}$ & & $\begin{array}{l}\text { Willing } \\
\text { Abandoner }\end{array}$ \\
\hline
\end{tabular}

continuum, although individuals do not necessarily progress through this continuum in a regular or linear fashion. Instead, readiness to change appears to be a complex construct that is influenced by numerous social interactions and experiences (see also Hernlund) ${ }^{27}$. Stages of change can, however, be used to describe segments or regions of this continuum. The stages defined for trans-theoretical or stage of change models for behaviours such as smoking or substance abuse do not adequately describe the process of behaviour change for FGC. Carey and colleagues ${ }^{4}$ point out that stages of change defined for such behaviours are complex in that they combine information on: 1) an individual's actual behaviour change and 2) an individual's selfreported intentions. Since the decision regarding FGC is often made by a decision-making group, we find it necessary to define stages that reflect an individual's opinion vis-à-vis the group decision, in addition to her or his own behaviour and intention Table 1. Our interpretation of the data suggests the following stages of change as applicable to decision- making around FGC in the Senegambia area:

Non-contemplation: These are individuals who are supporters of the continuation of FGC. The term "pre-contemplation" was originally proposed by Prochaska and DiClemente ${ }^{10}$ to describe individuals who are not considering attempting to quit smoking. We prefer the term "non-contemplation" to "pre-contemplation" since the latter seems to imply that individuals will necessarily eventually become contemplative. In our study sites, people are well aware of local and international efforts to end the practice of FGC. Hernlund ${ }^{28}$ (p. 240) writes that in urban areas, "few individuals are unaware of local campaigns to convince people of the need to eradicate 'female genital mutilation.' In rural areas, as well, many communities have been contacted by fieldworkers from groups trying to abolish FGC." Daffeh and colleagues report, however, that a staggering $93 \%$ of their respondents claimed to be unaffected by the campaigns (p. 22. $\left.{ }^{26}\right)$. Consequently, those who support the practice do so not because they are unaware of alternatives or efforts to change the practice. Instead, they have been exposed to, but were unpersuaded by, arguments for ending the practice. Within this category we see a range of responses to anticircumcision messages, ranging from simple rejection of arguments for ending the practice, to strong reactance to what are perceived as attacks on culture and, sometimes, religion:

\section{Non-contemplation}

Even if the majority of Gambians campaign against it, I and my family will not stop it because this is our tradition and we will make sure that we do what our tradition says. (Elderly, urban, Jola man, The Gambia).

Strong reactance

These campaigners are in the habit of spreading money into the villages, so that the people will forget

African Journal of Reproductive Health Vol. 10 No.2 August 2006 
their culture. Some of the people have been brainwashed, and they are already in for the eradication. For me, as a typical Mandinke, I can't abandon my culture. And if this process is harmful, the majority of my parents should have been dying like mosquitoes. (Elderly, rural, Mandinka woman village leader, The Gambia).

Contemplation: This stage describes individuals who are practitioners of FGC, but are experiencing ambivalence, and questioning aspects of the practice:

If they campaign against it, it is good, and if they don't campaign against it, it is also good for me. In these modern days, it is not safe to circumcise many people with one blade. There are several infections that can be transmitted during circumcision. To my understanding, if there are more disadvantages than advantages in the practice, a law can be implemented. People's health is a government concern. (Middleaged, rural, Wollof man, The Gambia).

Reluctant practitioner: This category does not fit with typical stages in models for individually based behaviors, but instead reflects the fact that the decision is often not solely in the hand of an individual. An individual's opinion can be overruled by the other decision-makers. Additionally, people may be in favour of abandoning the practice, but be reluctant to do so because of factors such as peer and/or family pressure. Consequently there can be people who oppose the continuation of the practice but continue it anyway:

The men don't even take it very seriously, because there are some men who don't even want their daughter to be circumcised. You will see, the mother will be the one to force the child to be circumcised and will say "because I am circumcised, she will also be circumcised." (Young, urban, Manjago/Jola woman, The Gambia).

The person [who decides not to practice] will not be comfortable in the community in which she is living because whenever she goes out, people will start pointing fingers at her: "that is that woman who

African Journal of Reproductive Health Vol. 10 No.2 August 2006 decided not to circumcise her daughters, while she [herself] is circumcised." Some will even encourage her daughters to be circumcised; they will tell them, "you are sitting here, your mother or parents don't want you to be circumcised, while they themselves are circumcised, and if they happen to pass away, you will be at a big loss, because you will know nothing in your tradition," and that can cause the daughters to be circumcised, which may bring problems between children and parents, because the parents will say their children don't respect them, that's why they didn't obey what they said to them (Young, urban, Manjago/Jola woman, The Gambia).

Willing abandoner of FGC: This describes individuals who are motivated to end the practice of FGC, and are able to act upon their intention:

I felt happy because the people of this community have agreed to stop it, so therefore I am also ready to stop it. It should be stopped because it has bad effects, like difficult births and tetanus, which may result in death. I have seen that here, a girl was circumcised and through that she died. (Middle-aged, rural, Sereer woman, Senegal).

Reluctant abandoner of FGC: People may abandon the practice of FGC even if they personally favor the continuation of the practice if other decision-makers or other social pressures force them to stop the practice. Cases of people who reluctantly abandon the practice include those in Senegal who still strongly value the practice and wish for its continuation, but abandon the practice because of fear of prosecution for breaking the law $^{29}$ :

No, it should not be stopped. But there is a law that says we should not practice it. And I myself do not support the law against it. It is just that we should not argue with the law because it is more powerful than us . . . . Even if I had another daughter I would not take her to circumcision because people are not doing it in our village now. And that is because of the law. (Elderly, rural, Sereer man, Senegal).

However, in addition to stages of change, another important concept is the level of 
tolerance of the behaviours of others. While some informants expressed strong opinions regarding whether members of their community should practise or abandon FGC, others "expressed" more tolerance:

Q: We understand that there are people who are trying to do campaigning against female circumcision. Can you tell me how you feel about that?

A: You know, they are saying what they want to say and people are doing what they have to do, so really I don't worry myself about them. It's a free country.

Q: Do you think that female circumcision should stop?

A: I think people who do not want to do it can stay without it and those who want to do it should be able to do it. (Young, Tillibonka, urban man, The Gambia).

The concept of readiness for change in terms of "stages" may seem to imply that the stages represent a sequence through which individuals progress in a linear fashion ${ }^{30}$. We find that for the case of FGC in our study sites, this is not necessarily true. For instance, it is possible for people who decided to abandon the practice to later become ambivalent about the decision. Additionally, individuals who are noncontemplative may remain so, and not necessarily ever become contemplative. Moreover, for people who have shifted their opinion, it is not necessarily the case that they have moved in a linear fashion from one stage to the next. In Senegal, for example, people whom we describe as "reluctant abandoners" have not necessarily experienced ambivalence. Consequently, viewing stages as a progressive sequence is an oversimplification of scenarios in which change (or lack of change) occurs. In addition, our current research findings, which include a number of instances of previously non-practicing women undergoing circumcision after marriage - even after the birth of several children - calls into question previous assumptions about a "cut-off" age after which it can be assumed that a woman will not undergo the practice.

\section{Discussion}

In recent years a proliferation of studies has employed the construct of readiness for change through "stage of change" or related measures for a broad array of "problem behaviours." Despite the popularity of this approach, a number of commentators have raised serious questions about methods of assessment and theoretical underpinnings as applied to an increasingly wide range of behaviours and settings ${ }^{4,23,30}$. With growing interest in understanding factors influencing behaviour change regarding FGC, it has been proposed that theoretical models of behaviour change may offer useful insights ${ }^{2,3}$. This study takes a first step in analysing the applicability and utility of a stage of change approach for describing the process of behaviour change regarding FGC in Senegal and The Gambia.

Our findings, based on analysis of extensive qualitative data, suggest that readiness to change for individuals is most clearly seen as operating along a continuum, and that broad stages of change characterise regions or segments of this continuum. The concept of stage of change as applied to FGC is a complex construct that rests not only on an individual's internal motivation to proceed with change, but also with her or his willingness and ability to do so. This construct simultaneously captures behaviour, motivation, and features of the environment in which the decision is being made. One important aspect of this environment is the decision-making group in which an individual is situated. Additionally, it is important to note that decision-making is also situated within and influenced by a broader social and political context. Consequently, the stages identified in this research reflect the multidimensional nature of readiness to change for FGC.

We note limitations of applying the concept of stage of change to FGC. First, a description

African Journal of Reproductive Health Vol. 10 No.2 August 2006 
of stages of change of an individual or a group of individuals provides a cross-sectional snapshot of readiness to change. It does not capture the fluidity of the composition of the decisionmaking group, nor the fact that an individual's opinion regarding FGC can shift as he or she moves between social actors and contexts. Such shifts can, however, be detected through longterm qualitative research which follows the same individuals over years at they negotiate their way through shifting realities $\left(\mathrm{see}^{28}\right)$. Second, stage of change theory has most often been applied to individual-based behaviors, often ones that are addictive such as smoking and alcohol or drug abuse. The decision as to whether to perform FGC is often not an individual one, and does not involve addiction. Additionally, while people can make repeat attempts to change behaviors such as smoking, the decision to perform FGC is irreversible. By contrast, the no-FGC decision may be revisited many times, including after marriage. And finnaly because decision-making often occurs among a group.... because decisionmaking often occurs among a group, there are important aspects of the decision-making process that are not addressed by a stage of change model. Specifically, whether and how a decision is negotiated, differentials in power between decision-makers, and how power dynamics shift over time are not captured by stage of change or other models of readiness to change. Consequently, critiques levelled at the use of RTC models for HIV prevention pertain in large part to the practice of FGC as well. Alternative methods are required to examine the dynamic and fluid dimensions of the decision-making process.

Despite these shortcomings, the application of stage of change theory may provide a useful means of describing the readiness for change of an individual or at an aggregate level, patterns of readiness for change in the community. Such descriptors may prove to be useful for identifying factors that motivate readiness for change, and for creating interventions strategies matched to African Journal of Reproductive Health Vol. 10 No.2 August 2006 the predominating stage of change. Additionally, the measurement of readiness for change may be useful for creating metrics of change short of complete abandonment of FGC. In the field of health psychology, a number of survey instrument have been developed for categorising individuals and quantifying RTC in a particular study population (see Carey, et. al. for a comprehensive review of instruments for measuring RTC regarding substance abuse) ${ }^{4}$. Due to differences in the proposed categories of change, however, staging algorithms developed for other individually based behaviours are not applicable to the case of FGC. Careful consideration will be required for the development of instruments that capture the categories of change identified in this study, and further empirical investigation is warranted.

\section{Acknowledgements}

This research is being supported by the National Science Foundation (grant number 0313503) and by the World Health Organization. Research affiliation was provided by Dr. C. Niang through Universite Cheikh Anta Diop, and by Dr. A. B. Senghore through Gambia College, Brikama Campus. We thank Molly Melching and staff at Tostan for providing us with helpful information about Tostan activity sites. We would like to acknowledge the important contributions of our hard-working and dedicated field team in Senegal and The Gambia: Alhagy Bah, Sally Bojang, , Modou Dem, Ebrima Jallow, Serreh Jebang and Naissatou Konteh. Also we wish to thank our research assistants from the University of Washington, Ratna Maya Magarati, Anthony Tessandori, and Katherine Wander, and the Carimar at the center for the study of Demography and Ecology for their tremendous help in data management and preliminary data analysis. We are indebted to Dr. Fuambai Ahmadu for her advice and logistical support in initiating data collection. And finally we wish to thank Dr. Corrne Kraiz for directing us to the abondant literature in stage-of change. 


\section{REFERENCES}

1. Population Reference Bureau. Abandoning Female Genital Cutting: Prevalence, Attitudes, and Efforts to End the Practice. (Population Reference Bureau, Washington, D.C., 2001).

2. WHO. Female Genital Mutilation: Programmes to Date: What Works and What Doesn't. A Review. (World Health Organization, Geneva, 1999).

3. Frontiers in Reproductive Health/PopulationCouncil. Using Operations Research to Strengthen Programmes for Encouraging Abandonment of Female Genital Cutting. (Report of a Consultative Meeting on Methodological Issues for FGC Research April 9-11, 2002, Nairobi, Kenya, 2002).

4. Carey, K. B., Purnine, D. M., Maiso, S. M. \& Carey, M. P. Assessing readiness to change substance abuse: A critical review of instruments. Clinical Psychology: Science and Practice 6, 245-266 (1999).

5. Janz, N. K. \& Becker, M. H. The health belief model: A decade later. Health Education Quarterly 11, 1-47 (1984).

6. Ajzen, I. \& Madden, T. J. Prediction of goaldirected behavior: Attitudes, intentions, and perceived behavioral control. Journal of Experimental Social Psychology 22, 453-474 (1986).

7. Fishbein, M. \& Ajzen, I. Belief, Attitude, Intention and Behavior: An Introduction to Theory and Research (Addison-Wesley, Reading, MA, 1975).

8. Izette, S. \& Toubia, N. Learning about Social Change. $A$ Research and Evaluation Guidebook Using Female Genital Cutting as a Case Study (RAINBO, New York, 1999).

9. Rogers, E. Diffusion of Innovation (The Free Press, New York, 1995).

10. Prochaska, J. O. \& DiClemente, C. C. Transtheoretical therapy: Toward a more integrative model of change. Psychotherapy Theory, Research and Practice 19, 276-288 (1982).

11. Prochaska, J. O. \& DiClemente, C. C. In search of how people change: Applications to addictive behaviors. American Psychologist47, 1102-1114 (1992).

12. Prochaska, J. O., Norcross, J. C. \& DiClemente, C. C. Changing for Good (Morrow, New York, 1994).

13. Brown-Peterside, P., Redding, C. A., Ren, L. \& Koblin, B. A. Acceptability of a stage-matched expert system intervention to increase condom use among women at high risk of HIV infection in New York City. AIDS Education and Prevention 12, 171-181 (2000).

14. Quinlan, K. B. \& McCaul, K. D. Matched and mismatched interventions with young adult smokers: Testing a stage theory. Health Psychology 19, 165-171 (2000).

15. Prochaska, J. O., et. al. Stage of change and decisional balance for 12 problem behaviors. Health Psychology 13, 39-46 (1994).

16. Diop, N. J., et. al. The Tostan Program: Evaluation of a Community Based Education Program in Senegal. (2003).

17. Toubia, N. F. \& Sharief, E. H. Female genital mutilation: Have we made progress yet? International Journal of Gynaecology and Obstetrics 82, 251261 (2003).

18. Parker, W. Rethinking conceptual approaches to behavior change: The importance of context. (Centre for AIDS Development, Research and Evaluation (CADRE), 2004).

19. Davies, P. \& SIGMA, P. On relapse: Recidivism or rational response? In AIDS: Rights, Risk and Reason (eds. Aggelton, P., Davies, P. \& Hart, G.) 133-141 (The Falmer Press, Washington D.C., 1992).

20. Ingham, R., Woodcock, A. \& Stenner, K. The limitations of rational decision-making models as applied to young people's sexual behaviour. In AIDS: Rights, Risk and Reason (eds. Aggleton, P., Davies, P. \& Hart, G.) 163-173 (The Falmer Press, Washington, D.C., 1992).

21. Melkote, S. R., Muppidi, S. R. \& Goswami, D. Social and economic factors in an integrated behavioural and societal approach to communi-cation in HIV/ AIDS. Journal of Health Communication 5, 17-27 (2000).

22. Yoder, P. S. Negotiating relevance: Belief, knowledge, and practice in international health projects. Medical Anthropology Quarterly 11, 131-146 (1997).

23. Yoder, P. S. From sexual behavior to sexual encounters: Issues in AIDS prevention research. Reviews in Anthropology 30, 225-241 (2001).

24. Shell-Duncan, B. Conceptual and Methodological Issues in Studying Sociocultural Determinants of Female Genital Cutting. Paper presented at the Conference:

African Journal of Reproductive Health Vol. 10 No.2 August 2006 
Are There "Stages of Change" in the Practice of Female Genital Cutting?: Qualitative Research Findings from Senegal. . . 71

Advancing Research on Female Genital Cutting (Bellagio, Italy, May 2002.).

25. Sylla, M. H. S. Excision au Sénégal. (ENDA, Dakar, 1990).

26. Daffeh, J., Dumbuya, S. \& Sosseh-Gaye, A. Listening to the Voice of the People: A Situation Analysis of Female Genital Mutilation in The Gambia. (WHO, UNFPA, UNICEF, 1999).

27. Hernlund, Y. Winnowing Culture: Negotiating Female "Circumcision" in The Gambia. Doctoral Dissertation (University of Washington, Seattle, 2003).

28. Hernlund, Y. Cutting without ritual and ritual without cutting: Female "circumcision" and the re-ritualization of initiation in the Gambia. In Female "Circumcision" in Africa: Culture, Controversy, and Change (eds. Shell-Duncan, B. \& Hernlund, Y.) 235-252 (Lynne Rienner Publishers, Boulder, CO, 2000).

29. Shell-Duncan, B. \& Hernlund, Y. Female genital cutting in Senegambia: Setting the stage for change. Paper presented at the Annual Meeting of the American Anthropological Association (November 30-December 4, Chicago, IL, 2005).

30. Weinstein, N. D., Rothman, A. J. \& Sutton, S. R. Stage theories and health behavior: Conceptual and methodological issues. Health Psychology 17, 290-299 (1998). 